\title{
VERBRUIKERSGERIGTHEID IN DIE MISSIESTELLINGS VAN HEDENDAAGSE ONDERNEMINGS: MITE OF REALITEIT?
}

\author{
C.J. Jooste \\ Departement Ondernemingsbestuur \\ Randse Afrikaanse Universiteit \\ JOHANNESBURG
}

\begin{abstract}
The aim of this anicle is to discuss the concepts of marketing and customer orientation towards the marketing function and to point out how the mission statements and objectives of modem firms reflect these orientations. The development of the marketing as well as customer orientation towards marketing is discussed. This is followed by an examination of the nature of mission statements and business objectives. It is argued that the mission statement as well as the company's objectives has to reflect the company's commitment towards serving customers' needs. It is apparent that this is not always the case in South Africa. Academics therefore have a challenge as well as an obligation to promote the concept of customer orientation and to advocate its reflection in the marketing planning process.
\end{abstract}

\section{INLEIDING}

Oor die jare heen het bemarking as ondernemingsfunksie tot een van die hoekstene van die moderne onderneming ontwikkel. So byvoorbeeld beweer Drucker (1988:57) dat bemarking een van die twee basiese funksies van die hedendaagse onderneming is. Die belangrikheid van bemarking as ondernemingsfunksie word algemeen aanvaar soos wat Brown (1987:26) inderdaad aantoon: "Indeed, the crucial importance of marketing is now almost universally acknowledged by top managers ... ."

Die moderne bemarkingsgerigte onderneming se aktiwiteite word deur die bemarkingskonsep gerig wat bepaal dat verbruikersbehoeftes die eerste prioriteit moet wees en dat die bevrediging van verbruikersbehoeftes 'n primêre doel van die onderneming behoort te wees (McCarthy \& Perrault, 1984:35-36). Die bemarkingskonsep as filosofie impliseer dus 'n totale verbruikersgerigte benadering tot die mark wat nie alleen tot die bemarkingsfunksie of -afdeling beperk is nie, soos wat Brown (1987:27) aanvoer: "... a genuine customer orientation involves all management functions ...".

Die belangrikheid van 'n bemarkings- en verbruikersgerigte benadering word volledig deur Peters en Austin (1985) bespreek en hul kom na afloop van hul ondersoek onder 
Amerikaanse (top)ondernemings tot onder andere die volgende gevolgtrekking: "The first ... strategic advantage we have observed is an obsession with customers. Customers, not markets. Not marketing ... Just customers. A 'market' has never been observed paying a bill. Customers do that" (Peters \& Austin, 1985:38).

Die praktiese implementering van die bemarkingskonsep en die bereiking van 'n omvattende verbruikersoriëntering word egter nog moeilik in die praktyk bewerkstellig (Pride \& Ferrell, 1987:17). Die problematiek aangaande die toepassing van die bemarkingskonsep word deur Webster (in Enis \& Cox, 1985:22) soos volg saamgevat: "... getting the marketing concept understood and accepted is still the biggest challenge faced by any organization ...".

Die doel met hierdie artikel is om die konsepte van bemarkings- en verbruikersgerigtheid te omskryf. Voorts sal aan die hand van sekondêre data ondersoek ingestel word na die mate waartoe verbruikersgerigtheid in die missie- en doelwitstellings van SuidAfrikaanse ondernemings geïnkorporeer word.

\section{DIE VERSKILLENDE ORIëNTASIES TOT BEMARKING}

Die evolusie van bemarking kan in vyf onderskeibare fases ingedeel word, te wete die produksie-, produk-, verkoops-, bemarkings- en die verbruikersgerigtefase. Hierdie verskillende fases en oriëntasies word vervolgens kortliks toegelig.

\subsection{Produksiefase/oriëntasie}

Hierdie eerste fase in die evolusie van bemarking het van die Industriële Revolusie tot in die laat twintigerjare van hierdie eeu geduur. Die algemeen geldende bestuurfilosofie kan soos volg opgesom word: "... if we can make it, it will sell" (McCarthy \& Perrault, 1987:27). Crissy (soos aangehaal deur Bennett, 1989:118) beskryf die filosofie van die produksiegeoriënteerde onderneming soos volg: "... the productionoriented company is self-centered and self-serving, displaying an attitude of indifference to customer needs and wants and the patron must adjust to what is offered, not the reverse." Die ondernemer is dus daarop ingestel om produksiedoelwitte, eerder as bemarkingsdoelwitte te bereik, en in die proses word geen aandag aan die behoeftes en begeertes van verbruikers gegee nie. 


\subsection{Produkfase/oriēntasie}

Gedurende hierdie fase poog die ondernemer om veral in die lig van toenemende mededinging te verseker dat die produk wat aangebied word aan die hoogs moontlike standaard voldoen omdat verbruikers daardie produk sal verkies wat die beste gehalte, bevrediging en eienskappe bied (Kotler, 1984:17).

Die onderneming wat in hierdie fase verkeer, konsentreer daarop om sy produkte te verbeter ongeag die behoeftes en begeertes van die verbruikers. 'n Goeie voorbeeld van so 'n oriëntasie kom in die Suid-Afrikaanse hotelbedryf voor waar die huidige graderingsvereistes van hotelle nie soseer op verbruikersbehoeftes en verwagtings gebaseer is nie maar eerder ten doel het om fisiese akkommodasiestandaarde daar te stel (Bennett, 1989:119).

\subsection{Verkoopsfase/oriēntasie}

Gedurende hierdie fase word die onderneming vir die eerste keer bewus van die verbruiker se rol. Die onderneming se pogings is nie meer op die verbetering van die produk gefokus nie maar eerder op die verkoop daarvan aan verbruikers. Hierdie benadering neem egter nog nie verbruikersbehoeftes in ag nie aangesien die produk eers vervaardig word en daarna word gepoog word om die produk te verkoop. Die uitgangspunt is dat verbruikers normaalweg nie genoeg van 'n onderneming se produk. te sal aankoop nie; daarom moet 'n aggressiewe verkoops- en promosiepoging onderneem word (Kotler, 1984:19).

\subsection{Bemarkingsfase/oriēntasie}

In plaas daarvan om verbruikers te oorreed om 'n onderneming se produkte en dienste aan te koop (verkoopsbenadering), kan 'n onderneming daarop konsentreer om eers te bepaal watter behoeftes verbruikers het, waarna produkte vervaardig kan word om aan hierdie behoeftes te voldoen. In die bemarkingsgeoriënteerde fase word verbruikersbehoeftes en die bevrediging daarvan die uitgangspunt.

Die vernaamste verskil tussen die verkoops- en bemarkingsoriëntasie is dat 'n verkoopsgerigte benadering hoofsaaklik op die behoeftes van die verkoper fokus en dat dit korttermyn-georiënteerd is. 'n Bemarkingsgerigte benadering daarenteen fokus op verbruikersbehoeftes en is meer langtermyn-georiënteerd er: toekomsgerig.

Die filosofie waarvolgens die bemarkingstaak in 'n bemarkingsgeoriënteerde onder- 
neming verrig word, staan as die bemarkingskonsep bekend. Die bemarkingskonsep is op vier basiese beginsels gebaseer te wete:

\subsubsection{Verbruikersoriēntering}

Verbruikersoriëntering impliseer die afstem van die onderneming se markaanbieding op die verbruiker se behoeftes, eise en voorkeure.

\subsubsection{Geïntegreerde bemarkingsbenadering}

'n Geïntegreerde bemarkingsbenadering vereis dat die totale onderneming en nie net die bemarkingsdepartement nie, daarop ingestel moet wees om die behoeftes van verbruikers te bevredig. Die bemarkingskonsep is dus nie beperk tot die bemarkingsdepartement of persone wat in direkte kontak met verbruikers is nie. Volkswagen Suid-Afrika het byvoorbeeld hierdie gaping tussen personeel wat nie in direkte kontak met verbruikers kom nie en die finale verbruiker oorbrug deurdat elke werknemer 'n sogenaamde 'verbruiker' het. Hierdie persoon is nie noodwendig die finale verbruiker nie maar verteenwoordig byvoorbeeld iemand wat afhanklik is van die inset van die persoon in die onderneming (Anon., 1988:19).

\subsection{Doelwitoriëntering}

Doelwitoriëntering impliseer dat die maksimalisering van winsgewendheid (effektiwiteit en doeltreffendheid in die geval van ondernemings wat nie op winsbejag ingestel is nie) oor die lang termyn nagestreef word (Marx \& van der Walt, 1989:2122). Hierdie strewe na rentabiliteitmaksimalisering behoort egter nie korttermyngeoriënteerd te wees nie, maar wel langtermyn-georiënteerd. In die nastrewing van hierdie ideaal is die bevrediging van verbruikersbehoeftes egter nog steeds van wesentlike belang. Stanton en Futrell (1987:14) stel dit soos volg: "If a company prospers in the long run, it must be doing a reasonably good job of satisfying its customers' current social and economic demands."

\subsubsection{Gemeenskapsoriëntering}

Gemeenskapsoriëntering impliseer dat die onderneming hom nie skuldig sal maak aan praktyke wat strydig is met heersende norme of morele of etiese standaarde nie. Die fokus van die bemarkingskonsep word dus verbreed om nie net verbruikers in te sluit 
nie maar ook die welvaart van die gemeenskap.

\subsection{Verbruikersgerigtheid - 'n resente fase in die evolusie van bemarking}

In die tagtigerjare het persoonlike aandag of diens (being close to the customer) aan die verbruiker sterk na vore getree, soos onder andere blyk uit die werke van Peters en Waterman (1982), Peters en Austin (1985), McBurnie en Clutterbuck (1988). Peters en Austin (1985:41) verwys na hierdie benaderings as verbruikersoriëntering (customer orientation) eerder as 'n bemarkingsgerigtheid.

Hierdie verbruikersoriëntering impliseer 'n soort beheptheid (obsession) met die verbruiker. In die nastrewing hiervan wend ondernemings pogings aan om verbruikers as 'belangrike individue' te hanteer en word alles in werking gestel om die verhouding tussen die onderneming en die verbruiker te verpersoonlik. Daar is 'n konseptuele verskil tussen bemarkings- en verbruikersgeoriënteerdheid. In die geval van bemarkingsgeoriënteerdheid val die klem op bemarking as instrument ter bevrediging van verbruikersbehoeftes. In die geval van verbruikersgeoriënteerdheid is die fokuspunt die verbruiker en sy behoeftes en is bemarking dan die instrument vir die daarstelling van verbruikersatisfaksie.

McBurnie en Clutterbuck (1988:103) beweer dat ondernemings wat sterk mededingende posisies beklee, selfs ten gronde kan gaan as hul hul 'closeness' aan verbruikers verloor. Albrecht (1985:64) beweer dat "service quality will be the next field of competition ... The new competitive weapon will be service management".

Strategieë wat daarop gemik is om aan 'n verbruikersgerigte filosofie gestalte te gee, moet net so deeglik beplan word as die verwesenliking van enige ander ondernemingsdoelwit. Ondernemingsukses hang grootliks af van die ondernemer se motivering en dryfkrag om sy verbruikers te dien. "The sale merely consummates the courtship, then the marriage begins. How good the marriage is depends on how well the relationship is managed by the seller " (Peters \& Austin, 1985:70).

In die bemarkingsgeoriënteerde onderneming val die klem op die belangrikheid van bemarking as die instrument ter bevrediging van verbruikersbehoeftes. Die verbruikersgeoriënteerde onderneming aan die ander kant fokus primêr op die verbruiker en sy behoeftes en sekondêr op bemarking as die instrument om in die behoeftes te voorsien. 'n Onderneming kan dus wel bemarkingsgerig wees (die klem val op bemarking), maar nog nie genoegsaam verbruikersgerig nie. 


\section{VERBRUIKERSGERIGTHEID EN DIE MISSIE VAN DIE ONDERNEMING}

Die missie van die onderneming dui die bestaansrigting van die onderneming aan. Die missie behoort 'n duidelike beeld te gee van die soort produk/diens van die onderneming en die rigting waarin die onderneming wil beweeg.

Die missie van ' $n$ onderneming is tradisioneel baie wyd gedefinieer; gewoonlik gekoppel aan die produk/diens van die onderneming, byvoorbeeld 'ons produseer en bemark kameras' of 'ons is in die eiendomsontwikkelingsonderneming'. Namate ondernemings al hoe meer bemarkings- en verbruikersgerig opgetree het, is dié tipe breë-missie-formulering bevraagteken.

Volgens Kotler, (1984:46) behoort die missie 'n omskrywing te bevat van

- die verbruikersgroep wat bedien word,

- die verbruikersbehoeftes wat bevredig sal word,

- die tegnologie wat aangewend sal word om die behoeftes te bevredig.

Die sentrale rol wat die verbruiker en sy behoeftes in missieformulering behoort te vervul, word deur Drucker (1988:72-85) beklemtoon. Hy postuleer dat missieformulering by die verbruiker begin en aan die hand van die volgende vrae geformuleer behoort te word:

- Wie is die verbruiker en wie behoort die verbruiker te wees?

- Waar is die verbruiker?

- Wat koop die verbruiker?

- Watter waarde (nut) word aan die verbruiker gebied?

- Watter behoeftes van die verbruiker is nog nie bevredig nie?

'n Grondige kennis van die verbruiker, sy behoeftes, beskouinge asook die vermoë van die onderneming se produkaanbieding om die behoeftes van verbruikers te bevredig is dus noodsaaklik alvorens 'n missie geformuleer kan word. 
Die missie van die onderneming behoort geformuleer te word uit 'n verbruikersbehoefte-bevredigende oogpunt eerder as 'n produk-produserende oogpunt.

$\mathrm{Na}$ 'n analise van etlike bronne kom Boshoff en Du Plessis (1989:6) tot die gevolgtrekking dat ' $n$ missie-stelling die volgende komponente behoort te bevat:

- Filosofie: die onderneming se basiese oortuigings, waardes en aspirasies.

- Selfkonsep: die onderneming se belangrikste sterk punte en mededingende voordeel.

- Identiteit of beeld van die onderneming.

- Verbruikers/mark wat bedien word.

- Produkte/dienste wat gebied word.

- Onderneming se ekonomiese doelwitte.

Met 'n opname wat David (1989:90-97) onder Amerikaanse ondernemings onderneem het, is bevind dat $83 \%$ van die vervaardigingsondernemings wat ondervra is, 'n verbruikersoriëntering in hul missie-stellings weerspieël. In 'n soortgelyke studie onder SuidAfrikaanse ondernemings wat op die Johannesburgse Effektebeurs genoteer is, bevind Boshoff en Du Plessis (1989:16-17) dat die uitspel van die onderneming se filosofie die element was wat in die meeste missies verskyn het $(70,4 \%)$, gevolg deur "concern for employees" (63\%) en "concern for survival, growth and profitability" $(61,1 \%)$. Net meer as die helfte van die missies $(51,9 \%)$ het 'n verwysing bevat na die produkte/dienste wat aangebied word, 'n derde na die bevrediging van verbruikersbehoeftes en $27,8 \%$ na die verbruiker of mark wat bedien word. Hieruit blyk ' $n$ baie lae verbruikersoriëntasie. "Of concern to many may be the lack of consumer perspective in the long term views of many of the respondent firms" (Boshoff \& Du Plessis, 1989:17).

\section{VERBRUIKERSGERIGTHEID EN DIE DOEL VAN DIE ONDERNEMING}

Die onderneming se missie moet in doelstellings en spesifieke doelwitte omgeskakel word.

Alhoewel 'n onderneming etlike doelstellings en gevolglik ock etlike doelwitte kan nastreef, hou die doelwitte normaalweg met een of meer van die volgende verband: 
- winsgewendheid,

- produktiwiteit,

- mededingende posisie,

- personeelontwikkeling en -verhoudinge,

- tegnologiese leierskap,

- sosiale verantwoordelikheid

(Smith, et al, 1985:79).

Uit hierdie ondernemingsdoelstellings vloei die bemarkingsdoelstellings voort wat normaalweg verband hou met

- winsgewendheid,

- verkope,

markaandeel,

groei

(Marx \& Van der Walt, 1989:516-517).

Hierdie bemarkingsdoelwitte is meestal daarop ingestel om die primêre ondernemingsdoelwit, naamlik rentabiliteitsmaksimalisering (winsmaksimalisering) te verwesenlik. Ondernemings wat egter sterk bemarkings- en verbruikersgerig is se bemarkingsdoelwitte en selfs ondernemingsdoelwitte behoort iets van hierdie oriëntering te weerspieël, byvoorbeeld om verbruikerstevredenheid te verhoog of klantediens te verbeter.

Dit is egter opvallend dat daar in die bemarkingsliteratuur wat in die loop van die studie geraadpleeg is byna geen eksplisiete verwysing gevind kan word na enige doelwitte wat op verbruikerstevredenheid of selfs verbruikersgerigtheid betrekking het. Die literatuur word meestal oorheers deur 'n bespreking van wins- en verkoopsgerigte doelwitte.

Gevolglik ontstaan die vraag of die doelstellings primêr moet wees om 'n sekere winsmikpunt te bereik en of die bevrediging van klante-behoeftes die primêre oogmerk behoort te wees met wins as 'n newe-effek daarvan. Insiggewend is die volgende aanhaling wat pertinent in die bekendmaking van Morkels se tussentydse finansiële resultate van 1990/91 verskyn: "Wins is 'n sinnelose omskrywing van die korporatiewe doelstelling. Sonder genoegsame klante in bestendige getalle is daar geen besigheid en geen wins nie."

Levitt (1983:5-7) laat hom sterk uit oor die doel (purpose) van die onderneming en beweer dat die doel van die onderneming "... is to create and keep a customer". Guaspari (1987:22) stem hiermee saam: "Business organizations exist for one reason 
and one reason alone - to deliver value to their customers." In teenstelling met ondernemings wat beweer dat dit die doel van die onderneming is om wins te maak, beweer Levitt dat wins 'n voorvereiste vir besigheid is, en nie 'n doel op sigself nie. Levitt (1983:6) verduidelik dit soos volg:

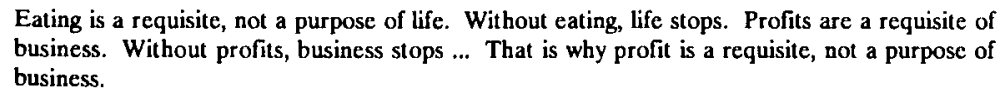

Eating is a requisite, not a purpose of life. Without eating, life stops. Profits are a requisite of business. Without profits, business stops ... That is why profit is a requisite, not a purpose of business.

Hoewel McCarthy en Perreault (1984:719-722) nie wins en verbruikersgerigtheid as ondernemingsdoel teen mekaar afspeel nie, beklemtoon hul tog die primêre doelwit van die moderne Amerikaanse onderneming: "... the present objective is to satisfy consumer needs as consumers see them ... Serving the customer is plainly the role of business" (McCarthy \& Perreault, 1984:719, 722).

Wins as ondernemingsdoel word ook deur Drucker (1988:56) gekritiseer wanneer hy beweer:

(It) is worse than irrelevant: it does harm. It is a major cause for the misunderstanding of the nature of profit in our society and for the deep-seated hostility to profit which are among the most dangerous diseases of an industrial society ... There is only one valid definition of business purpose: to create a customer.

Levitt (1983:6-7) beweer voorts dat wins as ondernemingsdoel moreel oppervlakkig en egosentries is. Wins as ondernemingsdoel is ook inhoudelik leeg, omdat wins op oneerlike en kortsigtige maniere gemaak kan word. Hierteenoor hou die 'skepping' en 'handhawing' van verbruikers as doel die volgende voordele in:

- Dit dwing die onderneming om te bepaal wat die verbruiker se werklike behoeftes en begeertes is.

* Die onderneming word gedwing om verbruikersbehoeftes te bevredig.

* Die doel verleen spesifieke riglyne en is moreel geregverdig (Levitt, 1983:7).

Die beskouing van Levitt is egter nie vry van kritiek nie. So byvoorbeeld beweer Davidson (1987:40) dat besighede wins moet makk, en dat "... the reckless pursuit of consumer benefit irrespective of profit results in bankruptcy". Hierdie stelling word egter met behulp van talle voorbeelde deur Peters en Austin (1985) as verkeerd bewys. Laasgenoemde beweer dat alle pogings, afgesien van die koste daaraan verbonde, aangewend moet word om die behoeftes van verbruikers te bevredig (Peters \& Austin, 1985:109). 
Verbruikersgerigtheid van hedendaagse ondernemers

Davidson (1987:40) gaan voort en beweer:

Only profitable firms can serve the consumer effectively ... it is ... quite possible to satisfy consumer needs superbly well while also returning above average profits. The fact that companies are profit-oriented does not mean that they lack interest in the consume:

Die argumente van sowel Levitt (1983) as Davidson (1987) hou sekere waarheidselemente in, maar dit is veral verbruikersgerigtheid wat in die formulering van die ondernemingsmissie en - doelwitte verwaarloos word.

In die huidige tydsgewrig is die primêre doelwit van die meerderheid ondernemings rentabiliteitsmaksimalisering oor 'n langtermyntydperk terwyl bemarkingsdoelwitte meestal op verkope gefokus is. In 'n ondersoek onder Suid-Afrikaanse vervaardigingsondernemings is die volgende bemarkingsdoelwitte deur die grootste persentasie respondente vermeld:

- verhoogde markaandeel

- omset/verkoopsvolume

* produkontwikkeling

* winsgewendheid

* klantediens

* beeld van onderneming

- verbetering van bemarkingsgeleenthede

kwaliteit van diens

- markpenetrasie

* distribusie

(Van Zyl, 1987:409).

Die resultate uit bogenoemde ondersoek beklemtoon die verwaarlosing van verbruikersgerigte doelwitte. Die beginsels van die bemarkingskonsep en 'n verbruikersgerigte benadering tot bemarking kan slegs uitgeleef word indien dit stukrag ondervind in die geformuleerde ondernemings- en bemarkingsdoelwitte. Vergelyk byvoorbeeld die volgende ondernemingsdoelwitte van British Airways:

* die lewering van die hoogste vlak van diens aan alle verbruikers,

* die spoedige en sensitiewe reaksie op die veranderende behoeftes van bestaande en potensiële verbruikers,

- die skepping van 'n diens- en mensgeoriënteerde werksomgewing (McBurnie \& Clutterbuck, 1988:25). 
'n Verbruikersgeoriënteerde benadering vorm een van die hoekstene van die bemarkingskonsep, en in die lig hiervan is dit dus vreemd dat daar in die bemarkingsliteratuur feitlik nie 'n aanduiding van verbruikersgerigte doelwitte te bespeur is nie. Christopher (1985:207-208) spreek hom ten gunste van'n formele beleid ten opsigte van verbruikersgerigtheid uit: "... it is essential for any business to have a clearly identified policy towards customer service. It is surprising perhaps that so few companies have defined policies (and objectives) on customer service". Die feit dat onder andere Kotler (1984:753) voorstel dat die meting van verbruikerstevredenheid as 'n vorm van beheer oor die bemarkingspoging gebruik kan word, impliseer ook dat daar verbruikersgerigte doelwitte geformuleer moet word.

Die feit dat die bemarkingskonsep 'n bestuursfilosofie is, vereis dus dat dit deel van die onderneming se missie moet uitmaak en selfs dat dit die rede vir die onderneming se bestaan moet wees. Indien die ondernemer nie bereid is om homself op hierdie wyse te verbind nie, sal die bemarkingskonsep waarskynlik nooit ten volle ontgin kan word nie. Levitt (1983:19) benadruk dit soos volg: "The purpose of a business is to create and keep a customer ... All other truths on this subject are mereley derivative." Berry (1986:5) kom tot die volgende gevolgtrekking: " ... marketing's true mandate ... is not to attract customers, but to have customers". Daarom is dit noodsaaklik dat formele doelwitte en beleid geformuleer moet word om hiercie verbruikers tevrede te hou.

\section{SAMEVATTENDE GEVOLGTREKKINGS}

Uit die voorafgaande bespreking het dit baie duidelik na vore gekom dat die bemarkingsproses wentel om die bevrediging van twee partye se behoeftes, naamlik die ondernemer self en die verbruiker. Enersyds word die bemarkingsaktiwiteit so beplan en georganiseer dat dit uiteindelik bydra tot die realisering van die ondernemer se rentabiliteitstrewe. Andersyds gaan die bemarkingsproses ook daaroor om produkte en dienste te lewer wat primêr in die behoeftes en begeertes van die verbruikerskorps voorsien en wat sekondêr nie tot nadeel van die breër gemeenskap strek nie.

Albei partye, ondernemer en verbruiker, is geregtig op die bevrediging van hul behoeftes. Die rentabiliteitsbehoefte van die ondernemer kan prinsipieël geregverdig word as sy 'vergoeding' vir insette gelewer. Hierteenoor is die verbruiker as ander party in die ruilverhouding geregtig op sy 'vergoeding', naamlik die verkryging van 'n nutswaarde wat sy behoeftes bevredig. Die bemarkingsproses is dus daarop gerig om op die verkoopsmark ruilverhoudings tot wedersydse voordeel van sowel klant as onderneming tot stand te bring.

In die bemarkingsproses kan die pendulum egter meer swaai na die bevrediging van 
die ondernemer se rentabiliteitstrewe as dié van die verbruiker. In so 'n geval word die basiese en billike reg van die verbruiker ontken. Die primêre doelstelling van die bemarkingsproses moet wees om in die behoefte van die verbruiker te voorsien. Uit die Christelike perspektief moet die hele proses gerig en gestuur word deur die Christen se verhouding tot God en sy naaste. Om dit tot eer van God en tot die beste voordeel van sy naaste te kan doen, moet die bemarkingsproses so beplan, georganiseer en uitgevoer word dat dit in die behoeftes van die verbruiker voorsien word.

Gevolglik sal prinsipieël verwag kan word dat 'n verbruikers- of klantegerigte bestuursfilosofie sentraal tot die bemarkingsproses moet staan. So 'n filosofie sal slegs verder as blote lippetaal gevoer kan word indien dit in die bestuursproses gekonkretiseer word. So behoort die filosofie gestalte te kry in die missiestelling en doel van die onderneming.

Waar daar in hierdie artikel aanduidings verskaf is dat bogenoemde egter nog glad nie by talle Suid-Afrikaanse ondernemings die geval is nie, lê daar 'n taak op die skouers van akademici om hierdie oriëntasie sowel as die konkretisering daarvan voortdurend te bevorder in die talle fasette van hul invloedsfeer. Die oogmerk moet wees om SuidAfrikaanse ondernemers te motiveer om die beginsel van verbruikersgerigtheid as uitgangspunt in hul bemarkingsbeplanning te aanvaar en prakties deur te voer in hul strategiese beplanningsprosesse.

\section{BIBLIOGRAFIE}

ANON. 1988. The search of excellence. Successful Salesmanship: 18-19. April.

ALBRECHT, K. 1985. Achieving excellence in service. Training and Development Joumal, 39(12):64-67. Fall.

BENNETT, J.A. 1989. 'n Ondersoek na die bemarkings- en verbruikersgerigtheid van die SuidAfrikaanse hotelbedryf. Bloemfontein. (Ongepubliseerde proefskrif (D.Com) - Universiteit van die Oranje-Vrystaat.)

BERRY, L.L. 1986. Retail businesses are service businesses. Joumal of Retailing, 62(1):3-6. Spring.

BOSHOFF, C. \& DU PLFSSIS, A.P. 1989. Aspects of mission statements of South African companies: an exploratory study. Voordrag gelewer by SAIB-konferensie, Port Elizabeth.

BROWN, R. 1987. Marketing - a function and a philosophy. The Quarterley Review of Marketing, 12 (3 en 4):25-30. Spring/Summer.

CRAVENS, D.W. HILLS, G.E. \& WOODRUFF, R.B. 1987. Marketing management. Homewood : Irwin.

CHRISTOPHER, M. 1985. The strategy of customer service (In Foxall, G., ed. Marketing in the service industries. London : Fank Cass. p. 205-213.)

DAVID, F.R. 1989. How companies define their mission. Long Range Planning, 22(1):90-97.

DAVIDSON, H. 1987. Offensive marketing or how to make your competitors followers. Middlesex : Penguin Books.

DRUCKER, P.F. 1988. Management: tasks, responsibilities, practices. London : Heineman Professional Publishing. 
ENIS, B.E. \& COX, K.K. 1985. Marketing classics: a selection of influential articles. Boston : Allyn and Bacon

GUASPARI, J. 1987. The role of "selling" quality improvement to employees. Management Review, (76):20-24

KOTLER, P. 1984. Marketing management: analysis, planning and control. New Jerscy : Prentice-Hall. LEVITT, T. 1983. The marketing imagination. New York: The Free Press.

MARX, S. \& VAN DER WALT, A. 1989. Bemarkingsbestuur. Kaapstad : Juta.

McBURNIE, T. \& CLUTTERBUCK, D. 1988. The marketing edge: vital lessons in marketing success. London : Penguin Books.

McCARTHY, E.J. \& PERREAULT, W.D. 1984. Basic marketing: a managerial approach Homewood : Irwin

McCARTHY, E.J. \& PERREAULT, W.D. 1987. Basic marketing: a managerial approach Homewood : Irwin.

PETERS, TJ. \& AUSTIN, N.K. 1985. A passion for exccllence: the leadership differencc. Glasgow: Fontana/Collins.

PETERS, T.J. \& WATERMAN, R.H. 1982. In scarch of excellence. Ncw York : Warner Books.

PRIDE, W.M. \& FERRELL, O.C. 1985. Marketing: basic concepts and decisions. Boston : Allyn and Bacon.

SMITH, G.D., ARNOLD, D.R. \& BIZZELL, B.G. 1985. Business strategy and policy. Boston : Houghton Miffin Company.

STANTON, W. J. \& FUTRELL, C. 1987. Fundamentals of marketing. New York : McGraw-Hill.

VAN ZYL, J.H. 1987. Die houding van bemarkingsbestuur van vervaardigingsondernemings in die RSA rakende faktore wat bemarkingsproduktiwiteit beïnvloed. Bloemfontein. (Ongepubliseerde procfskrif (D. Com.) - Universiteit van die Oranje-Vrystaat.) 
